\title{
ESTIMATING GLOMERULAR FILTRATION RATE AT THE TRANSITION FROM PEDIATRIC TO ADULT CARE
}

\begin{abstract}
Hans Pottel1,13, Jonas Björk'2,3,13, Arend Bökenkamp",13, Ulla Berg55, Kajsa Asling-Monemi5, Luciano Selistre6, Laurence Dubourg7,13, Magnus Hansson, Karin Littmann', Ian Jones ${ }^{9}$, Per Sjöström ${ }^{9}$, Ulf Nyman ${ }^{10,12,13}$ and Pierre Delanaye ${ }^{11,12,13}$

${ }^{1}$ Department of Public Health and Primary Care, Katholieke Universiteit Leuven Campus Kulak Kortrijk, Kortrijk, Belgium; 2Division of Occupational and Environmental Medicine, Lund University, Lund, Sweden; ${ }^{3}$ Clinical Studies Sweden, Forum South, Skane University Hospital, Lund, Sweden; ${ }^{4}$ Emma Children's Hospital, Amsterdam University Medical Center, Vrije Universiteit Amsterdam, Amsterdam, the Netherlands; ${ }^{5}$ Department of Clinical Science, Intervention, and Technology, Division of Pediatrics, Karolinska Instituted Karolinska University Hospital Huddinge, Stockholm, Sweden; ${ }^{6}$ Mestrado em Ciencias da Saude - Universidade Caxias do Sul Foundation, Coordenagao de Aperfeiçoamento de Pessoal de Nivel Superior, Brazil; ${ }^{7}$ Exploration Fonctionnelle Rénale, Groupement Hospitalier Edouard Herriot, Hospices Civils de Lyon, Lyon, France; ${ }^{8}$ Department of Laboratory Medicine, Division of Clinical Chemistry, Karolinska Instituted Karolinska University Hospital Huddinge, Stockholm, Sweden; ${ }^{9}$ Department of Laboratory Medicine, Örebro University Hospital, Orebro, Sweden; ${ }^{10}$ Department of Translational Medicine, Division of Medical Radiology, Lund University, Malmö, Sweden; and ${ }^{11}$ Nephrology-Dialysis-Transplantation, University of Liège, Centre Hospitalier Universitaire du Sart Tilman, Liège, Belgium
\end{abstract}

${ }^{12} \mathrm{UN}$ and PD share last authorship.

${ }^{13} \mathrm{HP}, \mathrm{JB}, \mathrm{AB}, \mathrm{LD}, \mathrm{UN}$, and PD are members of the European Kidney Function Consortium working group.

The current Kidney Disease Improving Global Outcomes (KDIGO) guidelines recommend the use of the bedside creatinine-based Chronic Kidney Disease in Children (CKiD) equation to estimate glomerular filtration rate (GFR) in children and the Chronic Kidney Disease Epidemiology Collaboration (CKD-EPI) equation in adults. However, this approach causes implausible changes in estimated GFR (eGFR) at the transition from pediatric to adult care. We investigated the performance of the KDIGO strategy and various creatinine-based eGFR equations in a crosssectional dataset of 5,764 subjects (age 10-30 years), using directly measured GFR (mGFR) as reference. We also evaluated longitudinal GFR slopes in 136 subjects who transitioned to adult care. Implausible changes in eGFR resulted from the large overestimation (bias $=+21 \mathrm{~mL} /$ $\mathrm{min} / 1.73 \mathrm{~m}^{2}$ ) and poor precision of the CKD-EPI equation in the 18-20 year age group, compared to CKiD in the $16-18$ year age group (bias $=-2.7 \mathrm{ml} / \mathrm{min} / 1.73 \mathrm{~m}^{2}$ ), resulting in a mean change of $23 \mathrm{~mL} / \mathrm{min} / 1.73 \mathrm{~m}^{2}$ at the transition to adult care. Averaging the CKiD and CKD-EPI estimates in young adults only partially mitigated this issue. The Full Age Spectrum equation (with and without height), the Lund-Malmö Revised equation, and an age-dependent weighted average of CKiD and CKD-EPI resulted in much smaller changes in eGFR at the transition (change of 0.6, $2.1,-0.9$ and $-1.8 \mathrm{~mL} / \mathrm{min} / 1.73 \mathrm{~m}^{2}$, respectively). The longitudinal analysis revealed a significant difference in average GFR slope between mGFR and the KDIGO strategy ( -2.2 vs. +2.9 $\mathrm{mL} / \mathrm{min} / 1.73 \mathrm{~m}^{2} /$ year), which was not observed with the other approaches. These results suggest that the KDIGO recommendation for GFR estimation at the pediatric-adult care transition should be revisited.

KEYWORDS: estimated GFR; measured GFR; pediatric-adult transition; serum, creatinine 
According to current KDIGO guidelines, eGFR is preferably done using the creatinine-based Chronic Kidney Disease in Children $\left(\mathrm{CKiD}_{\mathrm{scr}}\right)$ equation ${ }^{1}$ and the CKD-EPI equation ${ }^{2}$ in adults. However, this switch from the $\mathrm{CKiD}_{\text {scr }}$ to the CKD-EPI equation in young adults can lead to sudden eGFR increases at 18 years. As an example, an 18-year-old male with a body height (Ht) of $180 \mathrm{~cm}$ and a serum creatinine (Scr) concentration of $0.90 \mathrm{mg} / \mathrm{dl}$, has an eGFR, according to

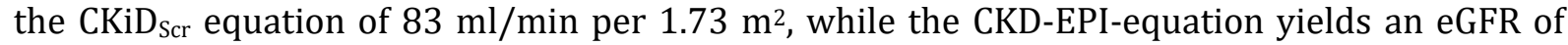
$124 \mathrm{ml} / \mathrm{min}$ per $1.73 \mathrm{~m}^{2}$. This discontinuity or abrupt change in GFR of $50 \%$ is physiologically implausible and may cause confusion to the patient and the care givers. Therefore, the Full Age Spectrum (FAS) equation was developed to guarantee continuity and applicability for the full age spectrum. ${ }^{3}$ At the age transition of 18 years, the FAS-eGFR of the example patient is 107.3 $\mathrm{ml} / \mathrm{min}$ per $1.73 \mathrm{~m}^{2}$. Selistre et al. $^{4}$ examined the applicability of the CKiDscr and CKD-EPIequation in over 10,000 subjects spanning the entire age range (3-90 years) and concluded that in young adults, aged 18 to 30 years, the CKD-EPI equation seriously overestimated mGFR, whereas the $\mathrm{CKiD}_{\text {scr }}$ equation underestimated mGFR. Very recently, Webster-Clark et al. ${ }^{5}$ presented a longitudinal cohort study of 242 patients with CKD aged 10 to 30 years as they transitioned from the pediatric to adult nephrology care. They found poor agreement between the $\mathrm{CKiD}_{\text {Scr }}$ and the CKD-EPI equations in patients before and during the transition period with CKD-EPI consistently yielding higher eGFRs, especially in male patients. In 2 studies by our research group, we confirmed the finding that CKD-EPI overestimates mGFR in young adults and kidney donors. ${ }^{6-8}$ In a recent review, ${ }^{9}$ we stated that eGFR equations performed best in the type of population for whom they were originally designed for, with preference for FAS in healthy and mildly kidney-diseased children (mGFR $\geq 75 \mathrm{ml} / \mathrm{min}$ per $1.73 \mathrm{~m}^{2}$ ) and with preference for the $\mathrm{CKiD}_{\text {scr }}$ equation in kidney-diseased children (with mGFR $<75 \mathrm{ml} / \mathrm{min}$ per $1.73 \mathrm{~m}^{2}$ ). The Lund-Malmö-Revised equation (LMR) has been originally designed for an adult population, ${ }^{8}$ but it has shown good performance in a pediatric population with normal GFR on average. ${ }^{10-11}$ As $\mathrm{CKiD}_{\text {Scr }}$ and CKD-EPI have opposite biases in young adults (18-30 years), Ng et al.12 recently proposed to average both equations in young adults in order to reduce bias and increase precision. However, their study was based on a rather limited dataset of 187 young adults, aged between 18 and 26 years, with 279 person-visits. They also did not specify at which age to switch to the adult eGFR equation, causing a new age transition problem at older age (26 years).

The current study evaluates the performance of various creatinine-based eGFR equations in adolescents during the pediatric-adult transition period, using measured GFR as the reference.

\section{Results}

\section{CROSS-SECTIONAL ANALYSIS}

The patient characteristics in the 5 centers are summarized in Table 1. Figure 1a to e presents the mGFR or eGFR plotted against age for 5764 children, adolescents, and young adults. We calculated the median GFR quantile versus age for the 10- to 18-year age interval and for the 18to 30-year age interval, separately. For mGFR, the left median quantile line corresponds to 92 (95\% confidence interval [CI]: 88.6-94.8) $\mathrm{ml} / \mathrm{min}$ per $1.73 \mathrm{~m}^{2}$ at 18 years, whereas the right median quantile line corresponds to 88 (95\% CI: 85.5-90.3) ml/min per $1.73 \mathrm{~m}^{2}$ at 18 years $(P>$ 0.05 ). For the KDIGO strategy, the left median quantile line corresponds to 77 (95\% CI: 75.3 78.9) $\mathrm{ml} / \mathrm{min}$ per $1.73 \mathrm{~m}^{2}$, demonstrating the underestimation by $\mathrm{CKiD}_{\mathrm{scr}}$, and the right median quantile using CKD-EPI corresponds to 118 (95\% CI: 115.1-120.1) ml/min per $1.73 \mathrm{~m}^{2}$, indicating a large change in eGFR at the transition age $(P<0.0001)$. Neither FAS-Age nor FAS-Ht show a sudden change in eGFR at the transition age. 
For FAS-Age, at the age of 18 years, the left median quantile is $94(95 \% \mathrm{CI}: 92.2-96.6) \mathrm{ml} / \mathrm{min}$ per $1.73 \mathrm{~m}^{2}$, and the right median quantile is $96(95 \% \mathrm{CI}: 91.9-98.8) \mathrm{ml} / \mathrm{min}$ per $1.73 \mathrm{~m}^{2}(P>$ 0.05). For FAS-Ht, at the age of 18 years, the left median quantile is 90 (95\% CI: 88.0-92.8) $\mathrm{m} / \mathrm{min}$ per $1.73 \mathrm{~m}^{2}$, and the right is 92 (95\% CI: $\left.90.2-94.6\right) \mathrm{ml} / \mathrm{min}$ per $1.73 \mathrm{~m}^{2}(P>0.05)$. This also applies to LMR with a left median quantile of $85(95 \% \mathrm{CI}: 83.0-88.0) \mathrm{ml} / \mathrm{min}$ per $1.73 \mathrm{~m}^{2}$ versus a right median quantile of 90 (95\% CI: 87.1-92.1) $\mathrm{ml} / \mathrm{min}$ per $1.73 \mathrm{~m}^{2}(P>0.05)$.

The same analysis was performed using 2 methods of calculating the average of the $\mathrm{CKiD}_{\text {scr }}$ equation and the CKD-EPI equation at age $\geq 18$ years (Figure $2 a$ and $b$ ). Calculating the arithmetic mean of both equations in the young adults as proposed by Ng et al.12 (Figure 2a) does lead to a lower right median quantile of 101 (95\% CI: $98.0-103.2) \mathrm{ml} / \mathrm{min}$ per $1.73 \mathrm{~m}^{2}$ at the age transition of 18 years, but this is still significantly higher than the CKiD $\mathrm{Scr}_{\text {-based left }}$ median quantile of 77 (95\% CI: 75.3-78.9) $\mathrm{ml} / \mathrm{min}$ per $1.73 \mathrm{~m}^{2}(P<0.0001)$. As the CKiD ${ }_{\text {scr }}$ equation demonstrates a slight underestimation at the transition age and the CKD-EPI equation has a large overestimation, using the average of both equations may decrease but does not solve the bias problem.

By contrast, the age-weighted mean (Figure $2 \mathrm{~b}$ ) almost abolishes most of the jump in eGFR at transition with a right median quantile of $84(95 \% \mathrm{CI}: 81.3-86.0) \mathrm{ml} / \mathrm{min}$ per $1.73 \mathrm{~m}^{2}(P=$ 0.00013).

Figure 3 shows the median quantile regression lines for bias plotted versus age. Whereas bias changes steadily for FAS-Age, FAS-Ht, and LMR there is a sudden change in bias (from - 6 to 22) when switching from CKiDscr to CKD-EPI at the age of 18 years. Bias is 0 for LMR, $+5 \mathrm{ml} / \mathrm{min}$ per $1.73 \mathrm{~m}^{2}$ for FAS-Ht, $+9 \mathrm{ml} / \mathrm{min}$ per $1.73 \mathrm{~m}^{2}$ for FAS-Age, $-6 \mathrm{ml} / \mathrm{min}$ per $1.73 \mathrm{~m}^{2}$ for $\mathrm{CKiD}_{\mathrm{Scr}},+22$ $\mathrm{ml} / \mathrm{min}$ per $1.73 \mathrm{~m}^{2}$ for CKD-EPI, $+9 \mathrm{ml} / \mathrm{min}$ per $1.73 \mathrm{~m}^{2}$ for the mean of CKiDscr and CKD-EPI and $-5 \mathrm{ml} / \mathrm{min}$ per $1.73 \mathrm{~m}^{2}$ for the age-weighted mean of CKiDscr and CKD-EPI. The performance of all equations and combinations in terms of bias, P10 and P30, overall and in subgroups defined by mGFR below and above $75 \mathrm{ml} / \mathrm{min}$ per $1.73 \mathrm{~m}^{2}$ is presented in Table 2. Above $75 \mathrm{ml} /$ min per $1.73 \mathrm{~m}^{2}$, LMR outperforms the other equations and combinations irrespective of age, whereas the $\mathrm{CKiD}_{\text {scr }}$ and the age-weighted mean approach yielded the best results for mGFR $<75$ $\mathrm{ml} / \mathrm{min}$ per $1.73 \mathrm{~m}^{2}$. In the Supplementary Methods and Results, we present these results separately for $45 \leq$ mGFR $<75 \mathrm{ml} /$ min per $1.73 \mathrm{~m}^{2}$ (Supplementary Table S1A) and for mGFR $<45 \mathrm{ml} / \mathrm{min}$ per $1.73 \mathrm{~m}^{2}$ (Supplementary Table S1B), confirming the preceding conclusion that $\mathrm{CKiD}_{\text {Scr }}$ and the age-weighted mean approach are the best for low GFR. In Table 3, we restricted the analysis to the transition age range between 16 and 20 years of age. These results were comparable with those of the entire group.

\section{LONGITUDINAL ANALYSIS}

We evaluated 136 subjects in a longitudinal setting (70 female and 66 male patients). Baseline age was $14.6 \pm 2.2$ years (range 8.2 to 17.9 ). These patients all have serial measurements going through the transition age of 18 years. Fifty-six, 32, 22, 13, and 13 patients had 2, 3, 4, 5, and more than 5 serial measurements, respectively, and were on average, 18.1, 17.2, 16.6, 17.0, 17.1, and 17.7 years old during the selected age range of 10 to 30 years. There were 450 serial measurements in total for these 136 participants, with overall mean age of 17.4 years. Average follow-up time for these 136 subjects during the restricted age range of 10 to 30 years was 5.8 years. Among these 136 patients, there were 52 subjects who had 1 GFR measurement between 16 and 18 years and another between 18 and 20 years. 
Table 1. Patient and method characteristics per center

\begin{tabular}{|c|c|c|c|c|c|c|c|}
\hline & Amsterdam & Leuven & Lund & Lyon & Stockholm & Örebro & Overall \\
\hline Number & 321 & 482 & 483 & 2919 & 1379 & 180 & 5764 \\
\hline Age (yr) & $15.3(10.1-15.7)$ & $\begin{array}{l}14.9 \\
21.0)\end{array}$ & $\begin{array}{l}18.0 \quad(10.0- \\
30.0)\end{array}$ & $\begin{array}{l}17.3 \\
29.9)\end{array}$ & $\begin{array}{l}14.9 \\
18.9)\end{array}$ & $\begin{array}{l}23.9 \quad(18.0- \\
30.0)\end{array}$ & $\begin{array}{l}16.7 \\
30.0)\end{array}$ \\
\hline $\begin{array}{l}\text { mGFR }(\mathrm{ml} / \mathrm{min} \\
\left.\text { per } 1.73 \mathrm{~m}^{2}\right)\end{array}$ & $89(13-152)$ & 81 (15-167) & $90(6-224)$ & $87(4-212)$ & $85(8-176)$ & $87(14-151)$ & $86(4-224)$ \\
\hline Female $(\%)$ & 36 & 43 & 36 & 46 & 40 & 44 & 43 \\
\hline Method & Inulin pc & ${ }^{51} \mathrm{Cr}$-EDTA pc & lohexol pc & $\begin{array}{l}\text { Inulin } \\
\text { rc/iohexol pc }\end{array}$ & lohexol pc & lohexol pc & - \\
\hline
\end{tabular}

Cr, creatinine; EDTA, ethylenediamine tetraacetic acid; mGFR, measured glomerular filtration rate; pc, plasma clearance; rc, renal clearance. Values are mean (minimum-maximum) unless otherwise indicated.

In Table 4, we present the mean slope of the regression lines, calculated per patient for mGFR, FAS-Age, FAS-Ht, LMR, the KDIGO strategy, the Ng et al. ${ }^{12}$ strategy, and the age-weighted strategy to evaluate the possible decreasing (slope $<-1$ ), increasing (slope $>+1$ ), or stable situation (slope between -1 and +1 ) of kidney function over the considered time period. We also calculated the slope of the bias (i.e., eGFR - mGFR), which should preferably be close to 0 , and the average root-mean-square error for all patients with at least 3 serial measurements. We further calculated the percentage of agreement with mGFR in defining the kidney function status as decreasing, stable, or improving. Table 5 contains the same summary statistics but restricted to the 52 patients with 1 measurement in the 16-to-18-year age period and 1 measurement in the 18-to-20-year age period.

Figure 1. Measured GFR (MGFR) (a) or estimated GFR (eGFR)-(b) creatinine-based Chronic Kidney Disease in Children (CKiDscr) and Chronic Kidney Disease Epidemiology Collaboration (CKD-EPI), (c) Full Age Spectrum (FAS)-Age, (d) FAS-Height (FAS-Ht), (e) Lund-Malmö-Revised equation (LMR)—for 3946 children (age <18 years) and for 1818 young adults (18 $\leq$ age $\leq 30$ years). The solid lines are the median quantiles calculated on mGFR or eGFR versus age separately for both age groups. 
a

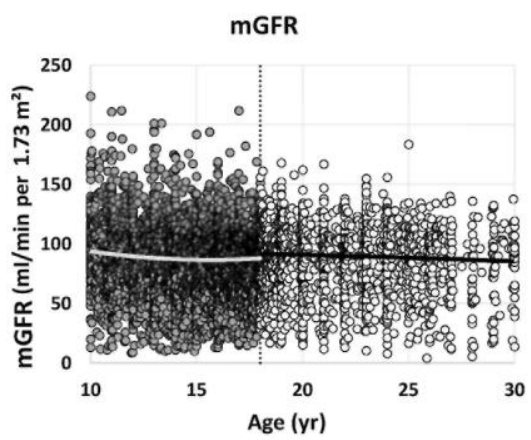

b

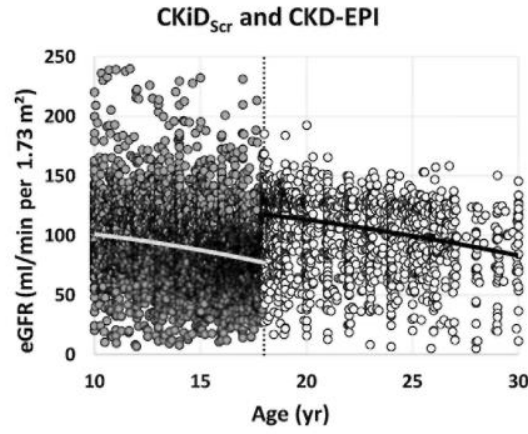

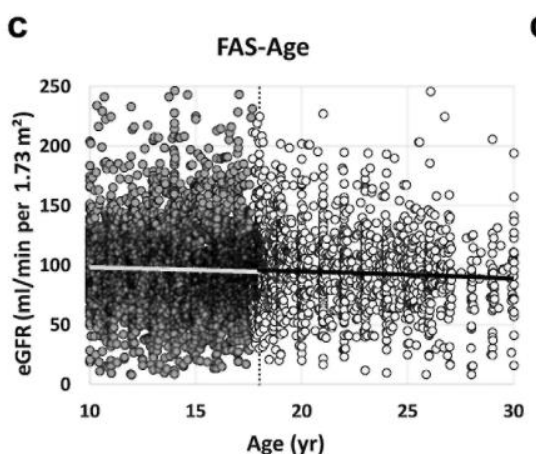

d
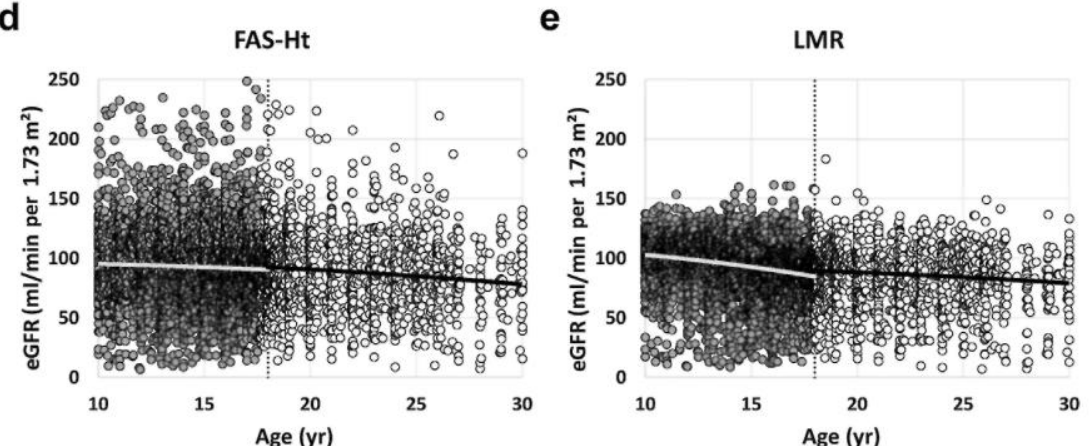

Figure 4a and b shows spaghetti plots of all 136 (or 52) GFR age profiles and the overall regression line for mGFR, the KDIGO strategy, FAS-Ht, and LMR. While mGFR declines (slope of $2.0 \mathrm{ml} / \mathrm{min}$ per $1.73 \mathrm{~m}^{2} /$ year $)$, the KDIGO strategy yields a significantly different $(P<0.0001)$ positive slope (slope of $+2.9 \mathrm{ml} / \mathrm{min}$ per $1.73 \mathrm{~m}^{2} /$ year), falsely suggesting improved kidney function when transitioning from pediatric to adult care in these patients. In Figure $4 \mathrm{~b}$, every subject had 1 measurement in the 16-to-18-year age range and 1 follow-up measurement in the 18-to-20-year age range. We hypothesized that in this short time period of $<4$ years, the kidney function did not change much or would slightly decrease (as these adolescents all had kidney pathologies). This hypothesis was well verified with mGFR, FAS-Age, FAS-Ht, and LMR, whereas the KDIGO strategy and $\mathrm{Ng}$ et al. ${ }^{12}$ strategy falsely suggested an improvement in kidney function.

Figure 2. eGFR-(a) creatinine-based Chronic Kidney Disease in Children (CKiD $\left.D_{S c r}\right)+$ average

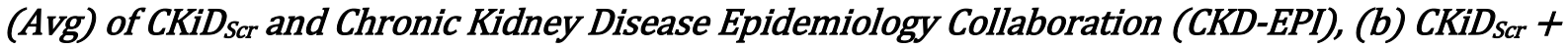
age-weighted average of CKiD $D_{s c}$ and CKD-EPI-for 3946 children (age <18 years) and for 1818 young adults (18 $\leq$ age $\leq 30$ years). The solid lines are the median quantiles calculated on eGFR versus age separately for both age groups.
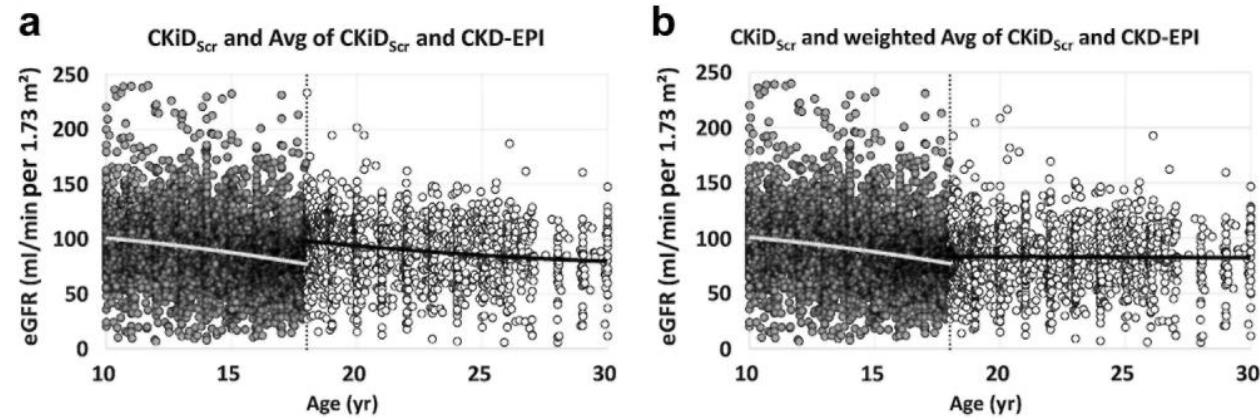


\section{Discussion}

This study was set up to study the performance of different methods to estimate GFR from Scr at the pediatric-adult care transition age of 18 years. The recommended strategy by KDIGO is to switch from the pediatric $\mathrm{CKiD}_{\text {Scr }}$ equation ${ }^{1}$ to the adult CKD-EPI equation. ${ }^{2}$ We compared the KDIGO strategy to the strategy recently proposed by $\mathrm{Ng}$ et al., ${ }^{12}$ and several equations (i.e., FASAge, FAS-Ht, LMR), which have been designed to cover the whole age span and are therefore supposed to be continuous at the pediatric-adult transition age. Finally, a novel approach using an age-weighted mean combining $\mathrm{CKiD}_{\mathrm{scr}}$ and CKD-EPI equation in young adults was tested.

Overall, the equations designed for all ages (FAS-Age, FAS-Ht, and LMR) do not show abrupt jumps at the pediatric-adult transition age range. 
Figure 3. Regression quantile lines for median bias (= estimated glomerular filtration rate [eGFR] - measured GFR [mGFR]) versus age for the different eGFR equations. Avg, average; CKD-EPI, Chronic Kidney Disease Epidemiology Collaboration; $C K i D_{S c r}$, creatinine-based Chronic Kidney Disease in Children; FAS, Full Age Spectrum; FAS-Ht, FAS-Height; LMR, Lund-Malmö-Revised equation.

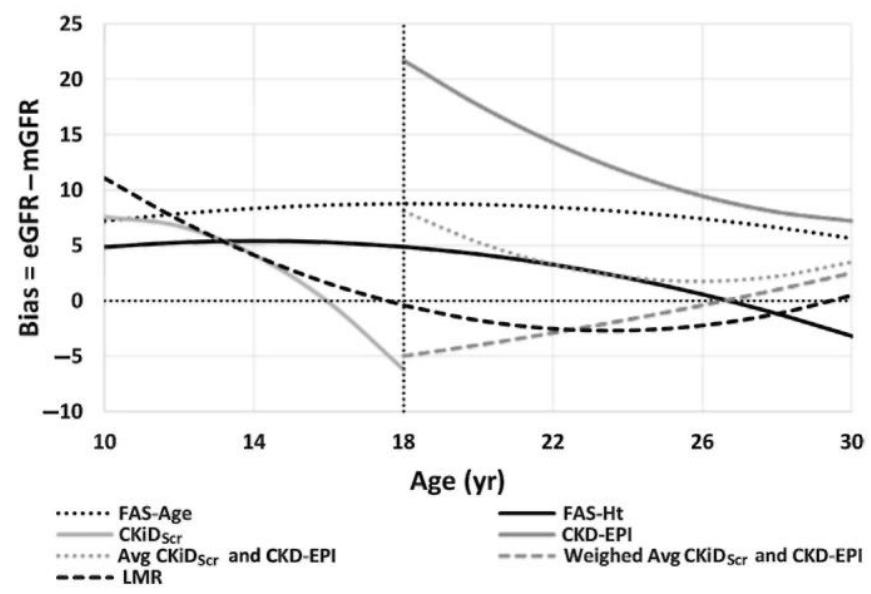

In line with previous studies we found that the $\mathrm{CKiD}_{\text {Scr }}$ equation underestimates GFR and CKDEPI overestimates GFR at the transition age of 18 years. ${ }^{4,9}$ This led Ng et al.12 to average both equations for young adults. The data from our cross-sectional analysis demonstrate that this approach only reduces the jump in bias from $23.2 \mathrm{ml} / \mathrm{min}$ per $1.73 \mathrm{~m}^{2}$ to $10.3 \mathrm{ml} / \mathrm{min}$ per 1.73 $\mathrm{m}^{2}$, which still remains significant and clinically important. Our multicenter study confirms the findings by Selistre et al. ${ }^{13}$ who challenged the $\mathrm{Ng}$ et al. ${ }^{12}$ strategy in an independent dataset of 543 subjects, aged between 18 and 26 years (the same age range used by $\mathrm{Ng}$ et al.) and concluded that the proposed solution by $\mathrm{Ng}$ et al. still overestimated mGFR. However, our sample of young adults is of Caucasian origin with an average $\mathrm{mGFR}=85.7 \mathrm{ml} / \mathrm{min}$ per $1.73 \mathrm{~m}^{2}$, whereas Ng et al. ${ }^{12}$ studied only 187 young adults (20\% African Americans) with more severe kidney malfunction (mGFR $=49 \mathrm{ml} / \mathrm{min}$ per $1.73 \mathrm{~m}^{2}$ ). In the $\mathrm{Ng}$ et al..$^{12}$ study renal clearance of iothalamate was used as the reference method versus plasma clearance of various exogenous markers (inulin, iohexol, ${ }^{51} \mathrm{Cr}$-ethylenedi-amine tetraacetic acid) in our study. This may (partly) explain the much higher overestimation of CKD-EPI in our study than was observed by Ng et al. in their study. ${ }^{12}$

The inadequacy of the KDIGO strategy is confirmed in the analysis of the longitudinal data where this strategy suggests an improvement (positive slope) in kidney function after transitioning whereas mGFR decreases (negative slope).

Our data clearly demonstrate that the CKD-EPI equation (recommended by KDIGO for the 18-to30 -year age period) is the main culprit for the implausible changes at 18 years. It strongly overestimates GFR in young adults with a large positive bias of $21 \mathrm{ml} / \mathrm{min}$ per $1.73 \mathrm{~m}^{2}$ in the age range of 18 to 20 years, decreasing to $19 \mathrm{ml} / \mathrm{min}$ per $1.73 \mathrm{~m}^{2}$ in the 20-to-24-year age group and $9.5 \mathrm{ml} / \mathrm{min}$ per $1.73 \mathrm{~m}^{2}$ in the 24-to-30-year age groups. This corresponds to a poor P30 accuracy of $60 \%$, increasing to $64 \%$ and $78 \%$, respectively. By contrast, using the $\mathrm{CKiD}_{\mathrm{Scr}}$ equation in young adults has significantly lower bias and higher accuracy. These results suggest that the CKD-EPI equation should not be used on its own in young adults, which is in line with the findings of Selistre et al. $^{4}$ 
Table 2. Performance of eGFR equations and combinations

\begin{tabular}{|c|c|c|c|c|c|c|c|c|c|c|c|c|c|c|c|c|c|c|c|c|}
\hline \multirow[b]{2}{*}{ Age } & \multirow[b]{2}{*}{ mGFR } & \multirow[b]{2}{*}{$n$} & \multicolumn{3}{|c|}{ FAS-Age } & \multicolumn{3}{|c|}{ FAS-Ht } & \multicolumn{3}{|c|}{ LMR } & \multicolumn{3}{|c|}{ KDIGO strategy ${ }^{3}$} & \multicolumn{3}{|c|}{ Ng et al. ${ }^{12}$ strategy ${ }^{b}$} & \multicolumn{3}{|c|}{ Alternative strategy"1 } \\
\hline & & & Bias & P10 & P30 & Bias & P10 & P30 & Bias & P10 & P30 & Bias & P10 & P30 & Bias & P10 & P30 & Bias & P10 & P30 \\
\hline \multicolumn{21}{|l|}{ All } \\
\hline $10-14$ & 89.7 & 1615 & 8.3 & 36.2 & 80.1 & 4.9 & 39.3 & 83.8 & 8.0 & 35.9 & 78.6 & 6.9 & 38.8 & 81.8 & 6.9 & 38.8 & 81.8 & 6.9 & 38.8 & 81.8 \\
\hline $14-18$ & 84.9 & 2331 & 9.8 & 33.0 & 73.9 & 6.3 & 35.8 & 77.0 & 1.9 & 41.7 & 84.9 & -0.5 & 38.2 & 83.7 & -0.5 & 38.2 & 83.7 & -0.5 & 38.2 & 83.7 \\
\hline $18-24$ & 87.1 & 1303 & 8.1 & 32.2 & 74.4 & 2.5 & 34.2 & 80.6 & -1.8 & 39.1 & 86.0 & $18.7(-6.3)$ & $24.0(30.2)$ & $64.4(82.7)$ & 5.2 & 40.7 & 80.1 & -3.9 & 34.8 & 84.7 \\
\hline $24-30$ & 82.3 & 515 & 7.8 & 33.2 & 74.6 & 1.6 & 31.3 & 80.4 & -1.2 & 39.0 & 86.8 & $9.5(-6.4)$ & $34.8(30.3)$ & 77.5 (84.9) & 1.8 & 38.6 & 84.1 & -0.3 & 38.0 & 85.8 \\
\hline $10-18$ & 86.8 & 3946 & 9.1 & 34.3 & 76.5 & 5.7 & 37.2 & 79.8 & 4.1 & 39.3 & 82.3 & 2.7 & 38.4 & 82.9 & 2.7 & 38.4 & 82.9 & 2.7 & 38.4 & 82.9 \\
\hline $18-30$ & 85.7 & 1818 & 8.0 & 32.5 & 74.5 & 2.2 & 33.3 & 80.5 & -1.8 & 39.1 & 86.2 & $15.2(-6.4)$ & $27.1(30.3)$ & $68.1(83.3)$ & 4.2 & 40.1 & 81.2 & -2.9 & 35.7 & 85.0 \\
\hline $10-30$ & 86.5 & 5764 & 8.7 & 33.7 & 75.8 & 4.7 & 36.0 & 80.0 & 2.0 & 39.2 & 83.6 & $6.4(-0.1)$ & $34.9(35.9)$ & $78.2(83.0)$ & 3.3 & 39.0 & 82.4 & 0.9 & 37.6 & 83.6 \\
\hline \multicolumn{21}{|c|}{$\mathrm{mGFR}<75 \mathrm{~m} \mathrm{l} / \mathrm{min}$ per $\quad 1.73 \mathrm{~m}^{2}$} \\
\hline $10-14$ & 53.5 & 511 & 10.1 & 26.6 & 67.5 & 6.1 & 33.3 & 77.7 & 17.0 & 14.3 & 46.8 & 7.9 & 31.1 & 73.4 & 7.9 & 31.1 & 73.4 & 7.9 & 31.1 & 73.4 \\
\hline $14-18$ & 53.4 & 795 & 11.7 & 23.8 & 61.1 & 7.2 & 31.7 & 68.6 & 8.2 & 30.4 & 69.7 & 6.1 & 37.4 & 77.5 & 6.1 & 37.4 & 77.5 & 6.1 & 37.4 & 77.5 \\
\hline $18-24$ & 53.2 & 415 & 14.5 & 14.9 & 50.1 & 6.7 & 27.2 & 71.6 & 6.7 & 32.5 & 69.6 & $18.6(2.0)$ & $14.2(28.2)$ & $45.1(80.2)$ & 9.4 & 28.2 & 61.2 & 3.3 & 33.0 & 77.8 \\
\hline $24-30$ & 49.3 & 188 & 10.8 & 16.0 & 56.4 & 6.8 & 24.5 & 71.3 & 4.2 & 39.9 & 73.9 & $10.1(0.3)$ & $20.2(37.8)$ & 63.8(85.1) & 5.4 & 36.7 & 73.4 & 4.0 & 39.4 & 76.1 \\
\hline $10-18$ & 53.4 & 1306 & 11.1 & 24.9 & 63.6 & 6.8 & 32.3 & 72.1 & 11.8 & 24.1 & 60.7 & 5.5 & 34.9 & 75.9 & 5.5 & 34.9 & 75.9 & 5.5 & 34.9 & 75.9 \\
\hline $18-30$ & 52.0 & 603 & 13.0 & 15.3 & 52.1 & 6.8 & 26.4 & 71.5 & 5.5 & 34.8 & 71.0 & $15.6(1.5)$ & $16.1(31.1)$ & $50.9(81.8)$ & 8.0 & 30.8 & 65.0 & 3.6 & 35.0 & 77.3 \\
\hline $10-30$ & 53.0 & 1909 & 11.7 & 21.8 & 60.0 & 6.8 & 30.4 & 71.9 & 9.8 & 27.5 & 64.0 & $7.8(4.4)$ & $29.0(33.7)$ & $68.0(77.7)$ & 6.3 & 33.6 & 72.4 & 5.0 & 34.9 & 76.3 \\
\hline \multicolumn{21}{|c|}{$\mathrm{mGFR} \geq 75 \mathrm{ml} / \mathrm{min}$ per $1.73 \mathrm{~m}^{2}$} \\
\hline $10-14$ & 106.4 & 1104 & 7.1 & 40.6 & 86.0 & 3.5 & 42.0 & 86.7 & 2.2 & 45.9 & 93.3 & 5.8 & 42.4 & 85.7 & 5.8 & 42.4 & 85.7 & 5.8 & 42.4 & 85.7 \\
\hline $14-18$ & 101.1 & 1536 & 7.7 & 37.8 & 80.5 & 5.4 & 37.9 & 81.4 & -2.8 & 47.5 & 92.8 & -3.5 & 38.6 & 86.8 & -3.5 & 38.6 & 86.8 & -3.5 & 38.6 & 86.8 \\
\hline $18-24$ & 102.9 & 888 & 4.6 & 39.1 & 83.3 & -1.0 & 37.4 & 84.8 & -7.7 & 42.2 & 93.7 & $16.6(-12.2)$ & $28.6(31.2)$ & $73.4(83.8)$ & 2.7 & 46.5 & 89.0 & -8.7 & 35.7 & 88.0 \\
\hline $24-30$ & 101.2 & 327 & 3.1 & 43.1 & 85.0 & -3.8 & 35.2 & 85.6 & -8.3 & 38.5 & 94.2 & $8.3(-14.9)$ & $43.1(26.0)$ & $85.3(84.7)$ & -2.9 & 39.8 & 90.2 & -5.3 & 37.3 & 91.4 \\
\hline $10-18$ & 103.3 & 2640 & 7.5 & 39.0 & 82.8 & 4.7 & 39.6 & 83.6 & -0.8 & 46.8 & 93.0 & 0.3 & 40.2 & 86.4 & 0.3 & 40.2 & 86.4 & 0.3 & 40.2 & 86.4 \\
\hline $18-30$ & 102.5 & 1215 & 4.2 & 40.2 & 83.8 & -1.7 & 36.8 & 85.0 & -8.0 & 41.2 & 93.8 & $15.1(-13.2)$ & $32.5(29.8)$ & $76.6(84.0)$ & 0.7 & 44.7 & 89.3 & -8.0 & 36.1 & 88.9 \\
\hline $10-30$ & 103.1 & 3855 & 6.3 & 39.4 & 83.1 & 2.9 & 38.7 & 84.0 & -2.9 & 45.1 & 93.3 & $4.5(-3.5)$ & $37.8(36.9)$ & $83.3(85.6)$ & 0.3 & 41.6 & 87.3 & -2.5 & 38.9 & 87.2 \\
\hline
\end{tabular}

CKiDscr, creatinine-based Chronic Kidney Disease in Children; eGFR, estimated glomerular filtration rate; FAS, Full Age Spectrum; FAS-Ht, FAS-Height; KDIGO, Kidney Disease Improving Global Outcomes; LMR, Lund-Ma I mo-Revised equation; MGFR, measured GFR.

${ }^{a}$ The combination of CKID-SCr (when age $<18$ years) and CKD-EPI (when age $\geq 18$ years).

${ }^{b}$ Combination of CKiD-SCr (when age <18 years) and the average of CKiD-SCr and VKD-EPI (when age $\geq 18$ years).

${ }^{c}$ Combination of CKiD-Scr (when age $<18$ years) and the weighed average of CKiD-Scr and CKD-EPI (when age $\geq 18$ years).

The statistics for the CKiDscr equation at age $>18$ years are given in parentheses.

Table 3. Performance of eGFR equations at the transition ages of 16 to 20 years 


\begin{tabular}{|c|c|c|c|c|c|c|c|c|c|c|c|c|c|c|c|c|c|c|c|c|}
\hline \multirow[t]{2}{*}{ Age } & \multirow[t]{2}{*}{ mGFR } & \multirow[t]{2}{*}{$n$} & \multicolumn{3}{|c|}{ FAS-Age } & \multicolumn{3}{|c|}{ FAS-Ht } & \multicolumn{3}{|c|}{ LMR } & \multicolumn{3}{|c|}{ KDIGO strategy } & \multicolumn{3}{|c|}{ Ng et al. ${ }^{12}$ strategy } & \multicolumn{3}{|c|}{ Alternative strategy } \\
\hline & & & Bias & P10 & P30 & Bias & P10 & P30 & Bias & P10 & P30 & Bias & P10 & P30 & Bias & P10 & P30 & Bias & P10 & P30 \\
\hline $\begin{array}{l}\text { All } \\
16-18\end{array}$ & 85.0 & 1272 & 10.4 & 33.0 & 73.7 & 5.5 & 36.2 & 78.0 & 0.1 & 42.8 & 88.0 & -2.7 & 37.0 & 85.5 & -2.7 & 37.0 & 85.5 & -2.7 & 37.0 & 85.5 \\
\hline $\begin{array}{l}\text { 18-20 } \\
\text { Change }\end{array}$ & 88.5 & 650 & $\begin{array}{l}11.0 \\
0.6\end{array}$ & 32.2 & 70.8 & $\begin{array}{l}3.4 \\
-2.1\end{array}$ & 36.0 & 79.7 & $\begin{array}{l}-0.8 \\
-0.9\end{array}$ & 41.5 & 87.1 & $\begin{array}{l}20.5(-5.3) \\
23.2(-2.6)\end{array}$ & $19.2(32.0)$ & $60.0(83.4)$ & $\begin{array}{l}7.6 \\
10.3\end{array}$ & 38.0 & 78.6 & $\begin{array}{l}-4.5 \\
-1.8\end{array}$ & 33.1 & 84.0 \\
\hline mGFR $<$ & $75 \mathrm{ml} / \mathrm{m}$ & n per 1 & $\mathrm{~m}^{2}$ & & & & & & & & & & & & & & & & & \\
\hline $16-18$ & 54.3 & 426 & 12.4 & 23.5 & 60.6 & 7.1 & 31.2 & 70.9 & 6.9 & 35.7 & 76.1 & 2.0 & 39.2 & 80.8 & 2.0 & 39.2 & 80.8 & 2.0 & 39.2 & 80.8 \\
\hline $18-20$ & 54.5 & 196 & 14.9 & 15.3 & 47.4 & 8.5 & 26.5 & 72.4 & 6.9 & 32.1 & 72.4 & $20.3(2.7)$ & $11.7(28.6)$ & $41.3(79.1)$ & 10.4 & 21.4 & 59.2 & 3.1 & 29.6 & 77.6 \\
\hline $\begin{array}{l}\text { Change } \\
\text { mGFR } \geq\end{array}$ & $75 \mathrm{ml} / \mathrm{m}$ & n per 1 & $\begin{array}{l}2.5 \\
\mathrm{~m}^{2}\end{array}$ & & & 1.4 & & & 0.0 & & & $18.3(0.7)$ & & & 8.4 & & & 1.1 & & \\
\hline $16-18$ & 100.5 & 846 & 8.8 & 37.8 & 80.3 & 4.3 & 38.7 & 81.6 & -4.0 & 46.5 & 94.0 & -6.6 & 35.9 & 87.9 & -6.6 & 35.9 & 87.9 & -6.6 & 35.9 & 87.9 \\
\hline $\begin{array}{l}18-20 \\
\text { Change }\end{array}$ & 103.2 & 454 & $\begin{array}{l}4.5 \\
-4.3\end{array}$ & 37.9 & 81.1 & $\begin{array}{l}1.1 \\
-3.2\end{array}$ & 40.1 & 82.8 & $\begin{array}{l}-6.2 \\
-2.2\end{array}$ & 45.6 & 93.4 & $\begin{array}{l}20.5(-10.1) \\
27.1(-3.5)\end{array}$ & $22.5(33.5)$ & $68.1(85.2)$ & $\begin{array}{l}5.0 \\
11.6\end{array}$ & 45.2 & 87.0 & $\begin{array}{l}-9.0 \\
-2.4\end{array}$ & 34.6 & 86.8 \\
\hline
\end{tabular}

CKiDscr, creatinine-based Chronic Kidney Disease in Children; eGFR, estimated glomerular filtration rate; FAS, Full Age Spectrum; FAS-Ht, FAS-Height; KDIGO, Kidney Disease Improving Global Outcomes; LMR, Lund-Ma I mo-Revised equation; mGFR, measured GFR. The statistics for the CKiDscr equation when age $\geq 18$ years are given in parentheses.

Based on the observation that the performance of the $\mathrm{CKiD}_{\text {scr }}$ equation decreases with age in young adults while the opposite is true for CKD-EPI, we propose a novel approach using a gradual and linear transition from the CKiDscr equation to the CKD-EPI equation over an age period of 20 years by applying appropriate age-weighting of both equations. As it is known that the GFR decline in healthy subjects starts around the age of 40 years, ${ }^{6}$ the weighting factor was designed to give full weight to the $\mathrm{CKiD}_{\text {sc }}$ equation at the age of 18 years and full weight to the CKD-EPI equation at the age of 38 years. The rationale for the choice for 38 years in the weighting factor (38 - Age)/20 is explained in the Supplementary Methods and Results and Supplementary Figure S1. 
This weighted approach showed less bias and improved accuracy in our dataset compared with the method proposed by $\mathrm{Ng}$ et al.12 and performed at least as well as FAS-Ht in both mGFR subgroups. As the newly proposed equation was designed on theoretical grounds and not developed in our dataset, the current study may be considered as a first (semi) validation of this alternative combination of the $\mathrm{CKiD}_{\mathrm{scr}}$ and CKD-EPI equation in young adults.

When comparing performance of the different approaches it becomes clear that the situation is quite different in mGFR subgroups.

When mGFR is normal (i.e., $\geq 75 \mathrm{ml} / \mathrm{min}$ per $1.73 \mathrm{~m}^{2}$ ), all proposed equations, except the KDIGO strategy, have a bias $<10 \mathrm{ml} / \mathrm{min}$ per $1.73 \mathrm{~m}^{2}$, a bias change of $<5 \mathrm{ml} / \mathrm{min}$ per $1.73 \mathrm{~m}^{2}$ and acceptable to excellent P30 accuracies between $80 \%$ and 95\%. At normal GFR in the 18-to-30year age group, the CKD-EPI equation shows a large positive bias of $15 \mathrm{ml} / \mathrm{min}$ per $1.73 \mathrm{~m}^{2}$, whereas the $C K i D_{\text {Scr }}$ equation has a large negative bias (underestimation by $13 \mathrm{ml} / \mathrm{min}$ per 1.73 $\mathrm{m}^{2}$ ). This explains the low bias of $0.7 \mathrm{ml} / \mathrm{min}$ per $1.73 \mathrm{~m}^{2}$ and good accuracy of $89 \%$ of the $\mathrm{Ng}$ et al. ${ }^{12}$ strategy, although this strategy still shows a bias change of $12 \mathrm{ml} / \mathrm{min}$ per $1.73 \mathrm{~m}^{2}$ at the age transition. The best performing equation for $\mathrm{mGFR} \geq 75 \mathrm{ml} / \mathrm{min}$ per $1.73 \mathrm{~m}^{2}$ is the LMR equation (with P30 = 94\%), still this method has a stronger bias of $-8.0 \mathrm{ml} / \mathrm{min}$ per $1.73 \mathrm{~m}^{2}$ above the age of 18 years, which is also noted for the age-weighted mean.

When mGFR is below $75 \mathrm{ml} / \mathrm{min}$ per $1.73 \mathrm{~m}^{2}$, bias change is still $<3 \mathrm{ml} / \mathrm{min}$ per $1.73 \mathrm{~m}^{2}$ with FAS-Age, FAS-Ht, and LMR, and the weighted mean, but problematic for the KDIGO strategy (18 $\mathrm{ml} / \mathrm{min}$ per $1.73 \mathrm{~m}^{2}$ ) and the $\mathrm{Ng}$ et al.12 strategy $\left(8.4 \mathrm{ml} / \mathrm{min}\right.$ per $\left.1.73 \mathrm{~m}^{2}\right)$. Interestingly, when applied to the complete 10-to-30-year age range, the $\mathrm{CKiD}_{\mathrm{scr}}$ equation shows the best results of all equations in patients with diminished kidney function (P30 $=77.7 \%$, bias of $4.4 \mathrm{ml} / \mathrm{min}$ per $1.73 \mathrm{~m}^{2}$ ), demonstrating the applicability of CKiDscr even in the 18-to-30-year age range for kidney-diseased young adults. FAS-Age, LMR, and the recommended KDIGO approach should not be used here. The weighted mean method $\left(\mathrm{P} 30=76 \%\right.$, bias $=5.0 \mathrm{ml} / \mathrm{min}$ per $\left.1.73 \mathrm{~m}^{2}\right)$ and the FAS-Ht equation $\left(\mathrm{P} 30=72 \%\right.$, bias $=6.8 \mathrm{ml} / \mathrm{min}$ per $1.73 \mathrm{~m}^{2}$ ) are the second-best equations for children and young adults with reduced kidney function both in terms of accuracy and bias at the transition age of 18 years. Summarizing these data, considering the performance of the different equations and strategies, both above and below $75 \mathrm{ml} / \mathrm{min}$ per $1.73 \mathrm{~m}^{2}$, FAS-Ht and the weighted mean strategy have the most consistent performance, smallest bias overall, and the best P10 and P30 values, which makes them most suitable in situations when no prior information on the expected range of GFR is available in a given patient.

Table 4. Summary statistics for 136 patients with serial data through the transition age

\begin{tabular}{|c|c|c|c|c|c|c|}
\hline mGFR & FAS-Age & FAS-Ht & LMR & KDIGO strategy & $\begin{array}{l}\mathrm{Ng} \text { et } \quad a l^{12} \\
\text { strategy }\end{array}$ & $\begin{array}{l}\text { Alternative } \\
\text { strategy }\end{array}$ \\
\hline$-2.0[-2.8 ;-1.1]$ & $-0.1[-1.5 ; 1.4]$ & $-0.8[-2.0 ; 0.5]$ & $-0.9[-1.6 ;-0.2]$ & $2.9[1.5 ; 4.2]$ & $0.6[-0.6 ; 1.8]$ & $\begin{array}{ll}-1.3 & {[-2.5 ;} \\
0.1] & \end{array}$ \\
\hline Slope bias & $1.9[0.5 ; 3.3]$ & $1.2[0.0 ; 24]$ & $1.1[0.2 ; 1.9]$ & $4.8[3.6 ; 6.0]$ & $2.5[1.5 ; 3.6]$ & $\begin{array}{l}0.7 \\
0.5 ; 1.8]\end{array}$ \\
\hline RMSE of bias ${ }^{a}$ & $10.6[8.8 ; 12.4]$ & $9.5[7.9 ; 11.1]$ & $9.3[7.9 ; 10.7]$ & $13.7[11.7 ; 15.7]$ & $11.1[9.5 ; 12.7]$ & $\begin{array}{l}9.8 \\
{[8.2 ; 11.5]}\end{array}$ \\
\hline $\begin{array}{l}\mathrm{D} / \mathrm{S} / \mathrm{I} \text { kidney function } 83 / 30 / 23 \\
\text { patients (n) }\end{array}$ & $53 / 35 / 48$ & $61 / 40 / 35$ & $72 / 37 / 27$ & $30 / 24 / 82$ & $48 / 31 / 57$ & $69 / 34 / 33$ \\
\hline Agreement (\%) ${ }^{\mathrm{b}}$ & 47.1 & 51.5 & 53.7 & 38.2 & 50.0 & 56.6 \\
\hline
\end{tabular}


mean-square error. Bracketed values are the 95\% confidence intervals.

a RMSE of bias is calculated on 84 (of 136) subjects who had at least 3 data points. bercentage of agreement represents the agreement between mGFR and eGFR in defining the status of kidney function over time (decreasing, stable, increasing).

However, both methods require height to estimate GFR, which is not always available in the clinical laboratory, but the LMR and FAS-Age equation do not and eGFR can thus be reported automatically by the clinical laboratory, along with Scr. Whereas LMR performs well in adults, 8 it is less suited for younger children and prepubertal children with diminished mGFR in the present study ${ }^{9,14}$.

Our findings from the cross-sectional study are confirmed in the longitudinal analysis on 136 subjects where an implausible jump is seen following the KDIGO strategy, but not in mGFR, the FAS equations, LMR, or the weighted approach. The average slope of $\mathrm{mGFR}$ of $-2.0 \mathrm{ml} / \mathrm{min}$ per $1.73 \mathrm{~m}^{2} /$ year was significantly different from 0 , indicating loss of kidney function over time in this cohort. The average slopes calculated for FAS-Age, FAS-Ht, LMR, and the weighted mean strategy were all negative and were not significantly different from the mGFR slope, whereas both the KDIGO strategy and the $\mathrm{Ng}$ et al.12 strategy showed positive slopes that were significantly different from the mGFR slope. This is even more obvious when the 52 patients with 1 measurement in the 16-to-18-year time period and with 1 measurement in the 18-to-20year time period are considered. Although the $\mathrm{Ng}$ et al.12 strategy reduced the average slope from $15.1 \mathrm{ml} / \mathrm{min}$ per $1.73 \mathrm{~m}^{2} /$ year to $7.0 \mathrm{ml} / \mathrm{min}$ per $1.73 \mathrm{~m}^{2} /$ year it was still strongly positive whereas the slope of $\mathrm{mGFR}$ and the other equations was not significantly different from 0 . This is also reflected in the agreement between the courses of eGFR and mGFR where the KDIGO approach classified only $38 \%$ of patients correctly, whereas this was up to $60 \%$ for the other methods. The Ng et al.12 approach was clearly superior to KDIGO but less accurate than the weighted mean, LMR, and FAS-Ht.

The strengths of this study are its large sample size and the availability of both cross-sectional and longitudinal data, passing the transition age at 18 years. Furthermore, Scr was measured with isotope dilution mass spectrometry-equivalent assays and GFR was directly measured with methods that have been shown to be sufficiently accurate. ${ }^{15}$ The data are coming from multiple centers, using different GFR measurement methods, representative for the method variability across Europe.

The limitations of this study are that the participants are all Caucasian, leaving some uncertainty about the applicability of the FAS and LMR in the mixed ethnic population of the USA. The ageweighted mean also warrants further validation in adults 31 to 38 years old, as this age span was part of the weighting scheme but was not included in the present dataset. mGFR using iothalamate was not available as this exogenous marker is not frequently used in Europe. We also did not evaluate the performance of other pediatric equations, such as the Schwartz-Lyon equation, ${ }^{16}$ which has been shown to perform better in a European pediatric population, especially in adolescents, but does not-based on unpublished results- solve the age-transition problem, as it underestimates GFR even more than the $\mathrm{CKiD}_{\text {Scr }}$ equation does above the age of 18 years, especially in female patients.

Table 5. Summary statistics for the 2-point serial data of 52 patients

\begin{tabular}{|c|c|c|c|c|c|c|c|}
\hline & mGFR & FAS-Age & FAS-Ht & LMR & KDIGO strategy & $\begin{array}{l}\mathrm{Ng} \\
\text { et al. }{ }^{12} \text { strategy }\end{array}$ & $\begin{array}{l}\text { Alternative } \\
\text { strategy }\end{array}$ \\
\hline Slope & $-2.2[-5.30 .9]$ & $0.8[-2.8 ; 4.4]$ & $-0.4[-3.7 ; 2.9]$ & $-0.3[-2.5 ; 1.8]$ & $15.1[11.4 ; 18.8]$ & $7.0[4.0 ; 10.0]$ & $-0.4[-3.4 ; 2.6]$ \\
\hline Slope bias & & $3.0[-0.3 ; 6.4]$ & $1.8[-1.2 ; 4.9]$ & $1.9[-07 ; 4.5]$ & $17.3[13.0 ; 21.7]$ & $9.2[5.9 ; 12.6]$ & $1.8[-1.1 ; 4.7]$ \\
\hline $\mathrm{D} / \mathrm{S} / \mathrm{l}$ kidney function & $28 / 8 / 16$ & $22 / 2 / 28$ & $22 / 7 / 23$ & $22 / 7 / 23$ & $4 / 1 / 47$ & $10 / 4 / 38$ & $24 / 6 / 22$ \\
\hline
\end{tabular}


patients (n)

D/S/l, decreasing, stable, improving; eGFR, estimated glomerular filtration rate; FAS, Full Age Spectrum; FAS-Ht, FAS-Height; KDIGO, Kidney Disease Improving Global Outcomes; LMR, Lund-Malmö-Revised equation; mGFR, measured GFR. Bracketed values show 1 measurement within the 16-to-18-year age group and 1 within the 18-to-20-year age group. aPercentage of agreement represents the agreement between mGFR and eGFR in defining the status of kidney function over time (decreasing, stable, increasing).

Figure 4. GFR age profiles for (a) 136 and (b) 52 subjects transitioning from pediatric to adult care: (upper left) measured GFR (mGFR), (upper right) Kidney Disease Improving Global Outcomes (KDIGO)-recommended equations, (bottom left) Full Age Spectrum-Height (FAS-Ht), and (bottom right) Lund-Malmö-Revised equation (LMR). 
a
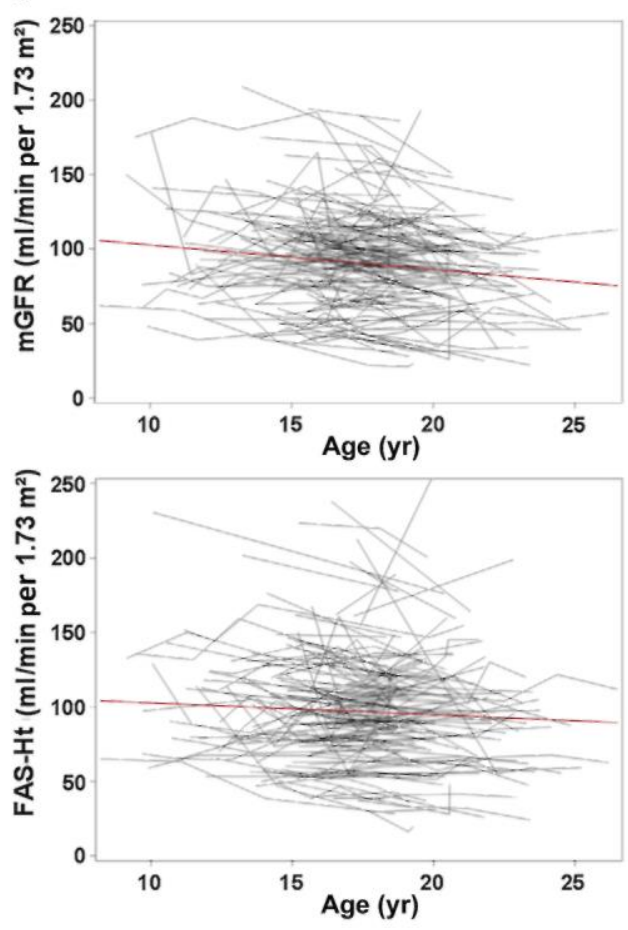

b
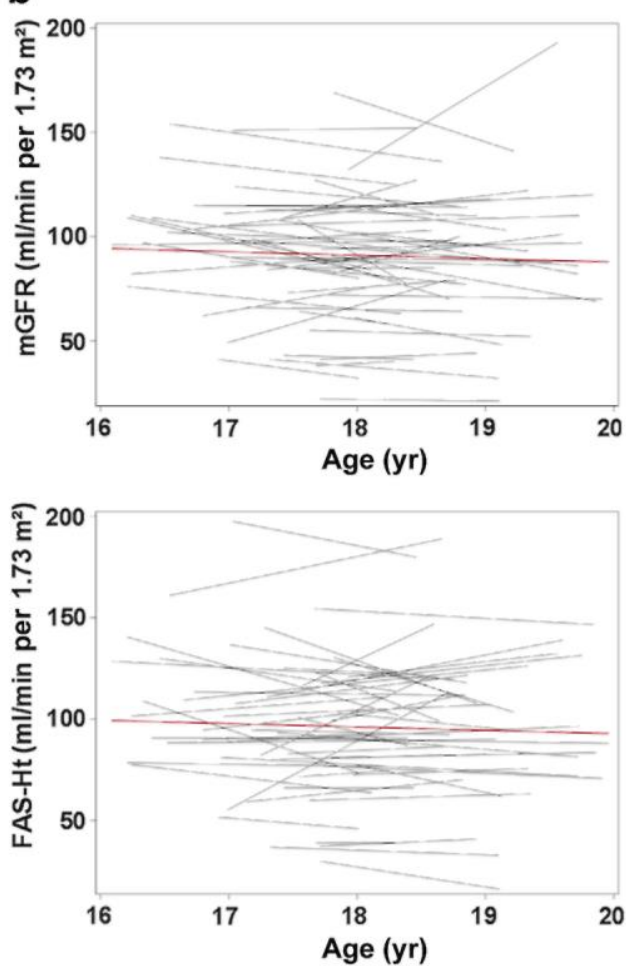
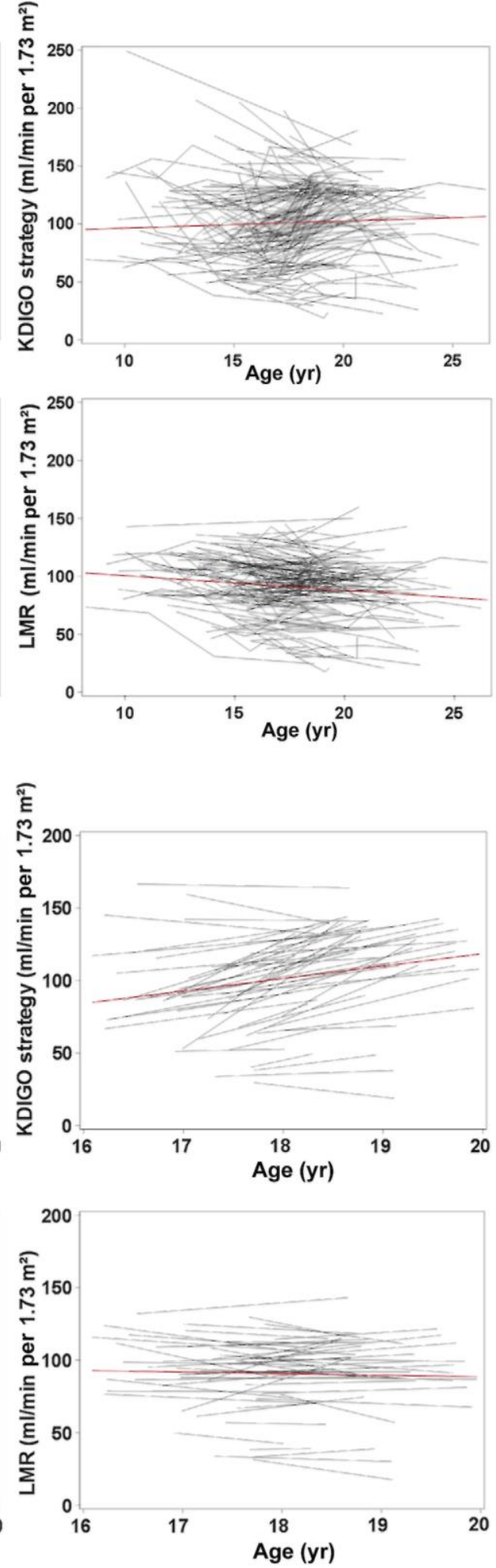
In conclusion, the KDIGO strategy to switch from the $\mathrm{CKiD}_{\text {scr }}$ equation to the CKD-EPI equation at the transition age of 18 years causes implausible changes in eGFR and should be abandoned. The recently proposed $\mathrm{Ng}$ et al.12 strategy using the average of CKiD ${ }_{\text {Scr }}$ and CKD-EPI in young adults reduces this sudden change but does not solve the problem, especially in children with reduced GFR. This strategy also does not recommend at what age to switch to adult equations. The FAS-Ht equation is continuous throughout the age transition and also the weighted-mean approach does not show unexpected changes in eGFR estimates. Both have good accuracy and bias, making them a perfect alternative to the KDIGO strategy. LMR is the optimal method in adolescents with normal kidney function and $\mathrm{CKiD}_{\mathrm{scr}}$ is in patients with reduced kidney function, but this requires prior knowledge of the kidney status (normal or reduced).

\section{Table 6. eGFR equations}

\begin{tabular}{|c|c|}
\hline Name & eGFR equation \\
\hline $\mathrm{CKiD}_{\mathrm{Scr}}{ }^{1}$ & $0.413 \times \mathrm{Ht} / \mathrm{Scr}$ \\
\hline CKD-EPI ${ }^{2}$ & $\begin{array}{c}141 \times(\mathrm{Scr} / 0.90)^{-1.209} \times 0.993^{\text {Age }} \text { for male patients, if } \mathrm{Scr} / 0.90 \geq 1 \\
141 \times(\mathrm{Scr} / 0.90)^{-0.411} \times 0.993^{\mathrm{Age}} \text { for male patients, if } \mathrm{Scr} / 0.90<1 \\
144 \times(\mathrm{Scr} / 0.70)^{-1.209} \times 0.993^{\mathrm{Age}} \text { for female patients, if } \mathrm{Scr} / 0.70 \geq 1 \\
144 \times(\mathrm{Scr} / 0.70)^{-0.329} \times 0.993^{\text {Age }} \text { for female patients, if } \mathrm{Scr} / 0.70<1\end{array}$ \\
\hline FAS-Age ${ }^{3,17,19}$ & $\begin{array}{c}107.3 /[\mathrm{Scr} / Q] \text { where } \\
Q=0.23+0.034 \times \text { age }-0.0018 \times \text { age }^{2}+0.00017 \times \text { age }^{3}-0.0000051 \times \text { age }^{4}, \text { for girls }<18 \text { years } \\
Q=0.21+0.057 \times \text { age }-0.0075 \times \mathrm{xage}^{2}+0.00064 \mathrm{xage}^{3}-0.000016 \times \mathrm{age}^{4}, \text { for boys }<18 \text { years } \\
Q=0.70 \text { for female patients when age } \geq 18 \text { years; } Q=0.90 \text { for male patients when age } \geq 18 \text { years }\end{array}$ \\
\hline FAS-Ht ${ }^{19}$ & $\begin{array}{c}107.3 /[\mathrm{Scr} / Q] \text { where } \\
Q=3.94-13.4 \times \mathrm{Ht}+17.6 \times \mathrm{Ht}^{2}-9.84 \mathrm{xHt}^{3}+2.04 \times \mathrm{Ht}^{4}(\text { with } \mathrm{Ht} \text { in } \mathrm{m})\end{array}$ \\
\hline $\mathrm{LMR}^{8}$ & $\begin{array}{c}\operatorname{Exp}[X-0.0158 \times \text { age }+0.438 \times \ln (\text { age })] \text { where } \\
X=2.5+0.0121 \times(150-\operatorname{Scr} \times 88.4) \text { for female patients with } \operatorname{Scr}<150 / 88.4 \\
X=2.5-0.926 \times \operatorname{In}(\operatorname{Scr} \times 88.4 / 150) \text { for female patients with } \operatorname{Scr} \geq 150 / 88.4 \\
X=2.56+0.00968 \times(180-\operatorname{Scr} \times 88.4) \text { for male patients with } \operatorname{Scr}<180 / 88.4 \\
X=2.56-0.926 \times \operatorname{In}(\operatorname{Scr} \times 88.4 / 180) \text { for male patients with } \operatorname{Scr} \geq 180 / 88.4\end{array}$ \\
\hline
\end{tabular}




\section{Methods}

\section{PARTICIPANTS}

Recently, a new European working group European Kidney Function Consortium was initiated aiming at optimizing estimating and measuring GFR, standardization and harmonization, and denning fixed or age-dependent GFR thresholds. The European Kidney Function Consortium took the initiative to collect data on subjects undergoing mGFR, including Scr, serum cystatin C, age, sex, height, weight, and diagnosis. For the purpose of this study, we selected a subset from our large database, namely subjects between 10 and 30 years of age in order to focus on the agetransition problem. This age-transition dataset contains 5 different cohorts of cross-sectional data from the Netherlands (Amsterdam, $n-321$ ), Belgium (Leuven, $n-482$ ), France (Lyon, $n$ - 2919), and Sweden (Lund, Örebro and Stockholm, $n$ - 2042), representing data from Southern, Central, and Northern Europe. Part of the data has been used and described in previous studies, $16-24$ while part of the data from Stockholm has not been published before. The present analysis includes 3946 measurements in children, aged between 10 and 18 years and 1818 measurements in young adults, aged between 18 and 30 years. These data are used in the cross-sectional analysis.

Another dataset from Lyon contained 136 subjects (non-transplanted patients) with serial data passing through the transition age of 18 years (i.e., at least 1 measurement of GFR before and at least 1 after the age of 18). These 136 subjects were studied in the longitudinal data analysis.

All subjects were referred for direct GFR measurement because of suspected or manifest kidney disease, during the period between 2004 and 2016. All procedures involving subjects and data were in agreement with the ethical principles for medical research on human subjects established in the World Medical Association Declaration of Helsinki. Anonymization and pooling of the data with the intention to study the performance of eGFR equations was reviewed and approved by the Regional Ethical Board in Lund, Sweden.

Scr was measured with an enzymatic assay (Roche [Basel, Switzerland] in Lyon, Leuven, and Stockholm; Abbott [Lake Bluff, IL] in Amsterdam and Lund), traceable to the isotope dilution mass spectrometry gold standard method. mGFR was obtained by different methods: inulin renal clearance in Lyon for part of the subjects, and plasma clearance in all other cases, using inulin in Amsterdam, ${ }^{51} \mathrm{Cr}$-ethylenediamine tetraacetic acid in Leuven, and iohexol in the other centers. The slope-intercept method with Bröchner-Mortensen correction, using 3 to 4 time points, was used for plasma clearance, except in Lund, where Jacobsson's iterative one-sample method 25 is used when the subject weighs more than $40 \mathrm{~kg}$, otherwise 2 samples were used.

The eGFR equations considered in the current analysis are presented in Table 6.

We analyzed the KDIGO strategy, which is the standard combination of $\mathrm{CKiD}_{\text {scr }}$ (for ages $<18$ years) with CKD-EPI (for ages $\geq 18$ years); the $\mathrm{Ng}$ et al ${ }^{12}$ strategy, that is, $\mathrm{CKiD}_{\text {Scr }}$ for ages $<18$ years and the average of $\mathrm{CKiD}_{\text {Scr }}$ and CKD-EPI for ages $\geq 18$ years; and a new age-dependent alternative strategy combining $\mathrm{CKiD}_{\mathrm{scr}}$ for ages $<18$ years and the age-dependent weighted average of CKiDscr and CKD-EPI for ages $\geq 18$ years. The weighing was as follows: eGFR $-\alpha \times$ CKiD $_{\text {Scr }}+(1-\alpha)$ x CKD-EPI, with $\alpha=(38-$ age $) / 20$. This weighing factor is 1 (equal to CKiD $_{\text {Scr }}$ ) when age $=18$ years and becomes 0 (equal to CKD-EPI) when age -38 years. Beyond 38 years, the CKD-EPI could further be applied. Besides, the FAS-Ht equation was validated as its performance has only been studied in children and adolescents, but not in young adults yet. 
We presented the data in figures with median quantile regression lines, calculated for both mGFR versus age, and eGFR versus age, separately for the age ranges 10 to 18 years and 18 to 30 years. The median quantile regression curve for bias (i.e., eGFR - mGFR) was plotted versus age, using a modification of a recently suggested approach. ${ }^{26}$ We used fractional polynomials for the quantile regression (proc quantreg in SAS [SAS Institute Inc., Cary, NC]) (linear and quadratic) and calculated the predicted median value with $95 \%$ CIs at the age of 18 years. These $95 \%$ CIs allowed us to estimate the modeling error at the "18-year end" of the quantile lines. Distinct 95\% CIs indicate a significant difference not related to quantile modeling error. We calculated bias and accuracy P10, P30 (i.e., percentage of estimates within $\pm 10 \%$ or $\pm 30 \%$ of mGFR) in the cross-sectional analysis, and the root-mean-square error for the different eGFR equations in the longitudinal analysis. The root-mean-square error (as a measure of accuracy for each equation) was calculated for each subject individually using all serial $(n>2)$ mGFR measurements of a given subject. Slopes of regression lines were compared between mGFR and eGFR, using a paired $t$-test. All calculations were done in SAS 9.4.

\section{DISCLOSURE}

All the authors declared no competing interests. This research received no specific grant from any funding agency.

\section{SUPPLEMENTARY MATERIAL}

\section{Supplementary Methods and Results.}

Contains the rationale for the choice of the age threshold of 38 years in the weighting factor and the performance statistics (bias, P10, P30) for the low glomerular filtration rate (GFR) region ( $45 \leq$ measured GFR [mGFR] $<75 \mathrm{ml} /$ min per $1.73 \mathrm{~m}^{2}$ and $\mathrm{mGFR}<45 \mathrm{ml} / \mathrm{min}$ per $1.73 \mathrm{~m}^{2}$ ).

Figure S1. Bias (= estimated glomerular filtration rate [eGFR] - measured GFR [mGFR]) against age for different strategies, calculated in the total dataset. Each data point is the average bias of the corresponding 2-year age range; for example, at 19 years, the average bias of the 18-to-20year age range is shown. All presented strategies use the creatinine-based Chronic Kidney Disease in Children $\left(\mathrm{CKiD}_{\text {scr }}\right)$ equation for ages $<18$ years and thus start from the common bias of $-2.7 \mathrm{ml} / \mathrm{min}$ per $1.73 \mathrm{~m}^{2}$.

Table S1A. Performance of estimated glomerular filtration rate (eGFR) equations and combinations. The statistics for the creatinine-based Chronic Kidney Disease in Children $\left(\mathrm{CKiD}_{\mathrm{scr}}\right)$ equation at age $>18$ years is given between brackets.

Table S1B. Performance of estimated glomerular filtration rate (eGFR) equations and combinations. The statistics for the creatinine-based Chronic Kidney Disease in Children $\left(\mathrm{CKiD}_{\mathrm{scr}}\right.$ ) equation at age $>18$ years is given between brackets. Supplementary material is linked to the online version of the paper at www.kidney-international.org. 


\section{References}

1. Schwartz GJ, Muñoz A, Schneider MF, et al. New equations to estimate GFR in children with CKD. J Am Soc Nephrol. 2009;20:629-637.

2. Levey AS, Stevens LA, Schmid CH, et al. A new equation to estimate glomerular filtration rate. Ann Intern Med. 2009;150:604-612.

3. Pottel H, Hoste L, Dubourg L, et al. An estimated glomerular filtration rate equation for the full age spectrum. Nephrol Dial Transplant. 2016;31: 798-806.

4. Selistre L, Rabilloud M, Cochat P, et al. Comparison of the Schwartz and CKD-EPI equations for estimating glomerular filtration rate in children, adolescents and adults: a retrospective cross-sectional study. PLOS Med. 2016;13:e1001979.

5. Webster-Clark M, Jaeger B, Zhong Y, et al. Low agreement between modified-Schwartz and CKD-EPI eGFR in young adults: a retrospective longitudinal cohort study. BMC Nephrol. 2018;19:194.

6. Pottel H, Hoste L, Yayo E, Delanaye P. Glomerular filtration rate in healthy living potential kidney donors: a meta-analysis supporting the construction of the full age spectrum equation. Nephron. 2017;135:105-119.

7. Pottel H, Delanaye P, Weekers L, et al. Age-dependent reference intervals for estimated and measured glomerular filtration rate. Clin Kidney J. 2017;10:545-551.

8. Nyman U, Grubb A, Larsson A, et al. The revised Lund-Malmö GFR estimating equation outperforms MDRD and CKD-EPI across GFR, age and BMI intervals in a large Swedish population. Clin Chem Lab Med. 2014;52:815-824.

9. Pottel H, Dubourg L, Goffin K, et al. Alternatives for the bedside Schwartz equation to estimate glomerular filtration rate in children. Adv Chronic Kidney Dis. 2018;25:57-66.

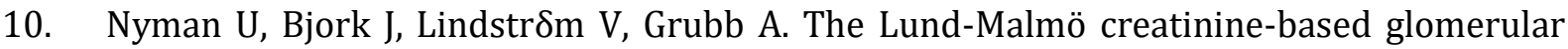
filtration rate prediction equation for adults also performs well in children. Scand J Clin Lab Invest. 2008;68:568-576.

11. Leion F, Hegbrant J, den Bakker E, et al. Estimating glomerular filtration rate (GFR) in children: the average between a cystatin C- and a creatinine-based equation improves estimation of GFR in both children and adults and enables diagnosing Shrunken Pore Syndrome. Scand J Clin Lab Invest. 2017,77:338-344.

12. Ng DK, Schwartz GJ, Schneider MF, et al. Combination of pediatric and adult formulas yield valid glomerular filtration rate estimates in young adults with a history of pediatric chronic kidney disease. Kidney Int. 2018;94:170-177.

13. Selistre L, Rabilloud M, De Souza V, et al. Regarding "Combination of pediatric and adult formulas yield valid glomerular filtration rate estimates in young adults with a history of pediatric chronic kidney disease." Kidney Int. 2018;94:827-828.

14. Pottel H. Measuring and estimating glomerular filtration rate in children. Pediatr Nephrol. 2017;32:249-263.

15. Soveri I, Berg UB, Bjork J, et al. Measuring GFR: a systematic review. Am J Kidney Dis. 2014;64:411-424. 
16. de Souza VC, Rabilloud M, Cochat P, et al. Schwartz formula: is one k-coefficient adequate for all children? PLoS One. 2012;7:e53439.

17. Pottel H, Delanaye $P$, Schaeffner E, et al. Estimating glomerular filtration rate for the full age spectrum from serum creatinine and cystatin C. Nephrol Dial Transpl. 2017;32:497-507.

18. Selistre L, De Souza V, Cochat P, et al. GFR estimation in adolescents and young adults. J Am Soc Nephrol. 2012;23:989-996.

19. Hoste L, Dubourg L, Selistre L, et al. A new equation to estimate the glomerular filtration rate in children, adolescents and young adults. Nephrol Dial Transplant. 2014;29:1082-1091.

20. Blufpand HN, Westland R, Van Wijk JA, et al. Height-independent estimation of glomerular filtration rate in children: an alternative to the Schwartz equation. J Pediatr. 2013;163:17221727.

21. Westland R, Schreuder MF, Bokenkamp A, et al. Renal injury in children with a solitary functioning kidney: the KIMONO study. Nephrol Dial Transplant. 2011 ;26:1533-1541.

22. Westland R, Abraham Y, Bokenkamp A, et al. Precision of estimating equations for GFR in children with a solitary functioning kidney: the KIMONO study. Clin J Am Soc Nephrol. 2013;8:764-772.

23. Grubb A, Horio M, Hansson L-O, et al. Generation of a new cystatin C-based estimating equation for glomerular filtration rate by use of 7 assays standardized to the international calibrator. Clin Chem. 2014;60: 974-986.

24. Grubb A, Nyman U, Bjork J. Improved estimation of glomerular filtration rate (GFR) by comparison of eGFRcystatin C and eGFRcreatinine. Scand J Clin Lab Invest. 2012;72:73-77.

25. Jacobsson L. A method for the calculation of renal determination by one plasma sample. Clin Physiol. 1981;3:297-305.

26. Bjork J, Grubb A, Sterner G, et al. Accuracy diagrams: a novel way to illustrate uncertainty of estimated GFR. Scand J Clin Lab Invest. 2017;77:199-204. 